\title{
The Development of a Land-use Regression Model for Ultrafine Particles in Toronto, Canada
}

\author{
Kelly Sabaliauskas, Cheol-Heon Jeong, Xiaohong Yao, \\ Christopher Reali, Tim Sun, and Greg J.Evans \\ Version Post-print/Accepted Manuscript \\ Citation Sabaliauskas, Kelly, et al. "Development of a land-use regression model \\ (published version) for ultrafine particles in Toronto, Canada." Atmospheric Environment \\ 110 (2015): 84-92. Doi: 10.1016/j.atmosenv.2015.02.018. \\ Copyright/License

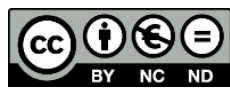 \\ This work is licensed under the Creative Commons \\ Attribution-NonCommercial-NoDerivatives 4.0 \\ International License. To view a copy of this license, visit \\ http://creativecommons.org/licenses/by-nc-nd/4.0/.
}

How to cite TSpace items

Always cite the published version, so the author(s) will receive recognition through services that track citation counts, e.g. Scopus. If you need to cite the page number of the author manuscript from TSpace because you cannot access the published version, then cite the TSpace version in addition to the published version using the permanent URI (handle) found on the record page.

This article was made openly accessible by $U$ of $T$ Faculty. Please tell us how this access benefits you. Your story matters. 


\section{The Development of a Land-use Regression Model for Ultrafine Particles in Toronto,}

2 Canada

3

4 Authors: Kelly Sabaliaukas, Cheol-Heon Jeong, Xiaohong Yao, Christopher Reali, and Tim

5 Sun, Greg Evans

6

7 Corresponding Author:

8 Kelly Sabaliauskas

9 Southern Ontario Centre for Atmospheric Aerosol Research, Department of Chemical

10 Engineering \& Applied Chemistry, University of Toronto, 200 College St., Toronto, Ontario,

11 M5S 3E5, Canada

12 Email: kelly.sabaliauskas@utoronto.ca

13 Phone: 416-978-5932

15 Key Words: Ultrafine Particles, diurnal variation, spatiotemporal variation, land use regression

\section{Abstract}

18 This study applies land-use regression (LUR) to characterize the spatial distribution of ultrafine

19 particles (UFP) in a large city. Particle number (PN) concentrations were measured in residential

20 areas around Toronto, Canada, between June - August 2008. A combination of fixed and mobile

21 monitoring was used to assess spatial gradients between and within communities. The fixed

22 monitoring locations included a central site, two downtown sites, and four residential sites

23 located 6 to $15 \mathrm{~km}$ from the downtown core. The mobile data included average PN concentrations

24 collected on 112 road segments from 10 study routes that were repeated on three separate days.

25 The mobile data was used to create the land-use regression model while the fixed sites were used

26 for validation purposes. The predictor variables that best described the spatial variation of PN

27 concentration $\left(\mathrm{R}^{2}=0.72\right.$, validated $\left.\mathrm{R}^{2}=0.68\right)$ included population density within $300 \mathrm{~m}$, total

28 resource and industrial area within $1000 \mathrm{~m}$, total residential area within $3000 \mathrm{~m}$, and major

29 roadway and highway length within $3000 \mathrm{~m}$. The LUR model successfully predicted the 
afternoon peak PN concentration (slope $=0.96, \mathrm{R}^{2}=0.86$ ) but over-predicted the 24-hour average $\mathrm{PN}$ concentration ( slope $=1.28, \mathrm{R}^{2}=0.72$ ) measured at seven fixed monitoring sites.

\subsection{Introduction}

Particulate matter (PM) exposure has been identified as a significant risk factor for the development of lung cancer and adverse health outcomes from cardiovascular and respiratory causes (Pope et al., 2002). These associations have been observed worldwide despite different sources of PM and different pollutant mixtures. More recently, ultrafine particles (UFP: particles with diameters less than $100 \mathrm{~nm}$ ) have been scrutinised due to their preferential deposition in the deepest regions of the human respiratory tract (Daigle et al., 2003), ability to promote the production of inflammatory biomarkers (Araujo et al., 2008; Bräuner et al., 2007; Delfino et al., 2010), and possible translocation to secondary organs within the body (Elder et al., 2006;

Oberdörster, 2004). The health consequences resulting from UFP exposure remain uncertain due to the lack of long-term temporal and spatially resolved data (HEI, 2014).

UFP concentrations are influenced by numerous combustion related sources, secondary formation pathways and transformation processes that alter their number, shape, size and chemical composition. In urban areas, vehicles, residential heating, cooking and industrial activities are common sources of UFP (Aalto et al., 2005; Buzorius, et al., 1999; Wang et al., 2011a; Sabaliauskas et al., 2012). Previous investigations have found both the particle number (PN) concentration and size of UFP exhibit significant seasonal, diurnal and weekday-weekend variation (Cyrys et al., 2008; Puustinen et al., 2007; Wang et al., 2011b). Although the number of urban areas with long-term temporal UFP datasets is growing, the majority of these data are from single monitoring sites. Assessing UFP concentration gradients across an urban area remains challenging. Efforts to characterize UFP concentration gradients in urban areas have measured UFP simultaneously at multiple sites (Buzorius et al., 1999; Cyrys et al., 2008; Johansson et al., 2007; Kim et al., 2002; Puustinen et al., 2007; Ragettli et al., 2014; Sabaliauskas et al., 2014), while walking along roadways with different traffic intensities (Kaur et al., 2006), and while driving (Kittelson et al., 2006; Pijola et al., 2006). 
Land-use regression (LUR) is a commonly used modelling technique that establishes empirical relationships between air pollutant concentrations and geographical predictor variables.

62 This technique has been applied to NO/NO2, PM2.5 and VOCs (reviewed by Hoek et al., 2008)

63 and recently applied to UFP (Abernethy et al., 2013; Hoek et al., 2011; Rivera et al., 2012).

64 Although the application of LUR methods presents an opportunity to characterize the range of

65 UFP concentrations that may exist within a city, numerous challenges relating to

66 instrumentation, logistics and statistics remain. To develop a reliable LUR model for any

67 pollutant, the number of sites is an extremely important parameter. Unlike the passive NO/NO2

68 badges that enable reliable simultaneous sample collection over long time horizons (weeks) and

69 at many sites (at least 20, but 100 is common), existing UFP instrumentation is expensive and

70 often requires substantial user intervention to collect accurate results. Consequently, existing

71 UFP LUR models developed for large urban areas rely on measurements collected at many sites

72 (>20) over short time horizons (hours) (Abernethy et al., 2013; Rivera et al., 2012) or at many

73 sites (50) over longer time scales (weeks) but non-concurrently (across multiple seasons) (Hoek

74 et al., 2011).

The abovementioned model development approaches result in a few unavoidable analysis challenges. Firstly, UFP exhibits a strong diurnal pattern from a combination of vehicle emissions and secondary particle formation (Jeong et al., 2010; Kulmala et al., 2004). Studies that rely on a short-duration measurement to characterize the UFP concentration at each site need to either collect measurements at all sites at roughly the same time of day or apply a correction

81 factor to make the mornings and afternoons comparable. However, the shape of the diurnal trend

82 can vary substantially between days and even between sites due to localized differences in

83 meteorology and emissions (Jeong et al., 2010; Ketzel et al., 2004a; Sabaliauskas et al., 2012).

84 Therefore, simply applying the same diurnal correction factor across all sites may not be

85 appropriate. Secondly, UFP exhibit an inverse relationship with temperature, with the highest PN 86 concentrations typically observed during the cooler winter months (Sabaliauskas et al., 2012;

87 Wang et al., 2011b). As a consequence, measurements need to be collected during periods with

88 similar meteorological conditions, repeated at the same location over multiple seasons, or 89 corrected (Hoek et al., 2011). Thirdly, the PN concentration can be impacted by the presence of 90 larger particles (Kulmala et al., 2001). The particle mass concentration can vary on a seasonal 
91 basis with higher temperatures favouring the formation of secondary aerosol. As a result, despite

92 measuring the UFP concentration under similar meteorological conditions, the PN concentration

93 may be suppressed due to the presence of large particles on one day and enhanced by their

94 absence on another. Finally, nucleation and growth events can dramatically impact the observed

95 PN concentration during the afternoon periods (Jun et al., 2014) and may result in more

96 homogeneous PN concentrations and size distributions across a region (Jeong et al., 2010).

97

This study describes the development of an LUR model for UFP in Toronto, Canada. UFP has been measured continuously in downtown Toronto since 2006. Long-term trends suggest a gradual reduction in the total number concentration between 2006 and 2011, likely due to changes in the vehicle fleet, reductions in coal-fired power plant usage and the economic downturn that impacted the United States and Southern Ontario (Sabaliauskas et al., 2012). A recent analysis of UFP measurements collected at six fixed residential field sites in Toronto suggests that vehicle counts may be an important predictor of only a portion of the UFP concentration (Sabaliauskas et al., 2014). This study applies a hybrid methodology and relies on the measurements collected at the same six fixed field sites supplemented with mobile monitoring to better characterize and establish spatial relationships across the city. Specifically, an LUR model was created based upon mobile measurements and tested against measurements

\subsection{Methodology}

\subsection{Study Design}

UFP measurements were collected using a combination of fixed site and mobile

114 monitoring (Figure 1) in Toronto, Canada. The fixed monitoring portion of the study was

115 executed at a central site, two downtown sites (A, B) and four residential sites $(\mathrm{C}, \mathrm{D}, \mathrm{E}, \mathrm{F})$ for 1 -

1163 weeks throughout the summer of 2008 (Figure 2). The residential sites were located between 6

117 and $15 \mathrm{~km}$ away from the downtown core (Sabaliauskas et al., 2014). The mobile phase of the

118 study assessed spatial gradients within neighbourhoods by collecting UFP measurements while

119 walking along roadways with different traffic densities near and between the fixed field sites.

120 Two routes were designed within each neighbourhood to ensure that locations both upwind and 
121 downwind from major sources such as expressways, major arterial roads and railroads were

122 visited. The maximum distance between the paired mobile measurements varied by route but 123 ranged between 0 and $6 \mathrm{~km}$. Each route was followed on three separate days.

\subsection{Instrumentation}

Multiple particle sizing and counting instruments were deployed at the sites for the study

127 (Figure 2). The Central Site was located at the Southern Ontario Centre for Atmospheric

128 Aerosol Research (SOCAAR) near downtown Toronto. The air sampling inlet was 6m above the

129 ground and 20m from a major arterial roadway with a weekday traffic volume of 20,000 vehicles

130 per day. UFP was monitored continuously at the Central site using a Fast Mobility Particle Sizer

131 (FMPS, Model 3091, TSI Incorporated, Shoreview, MN, USA). The FMPS provided particle

132 number based size distributions over the range of 5.6 to $560 \mathrm{~nm}$ with 1 -second time resolution.

133 One-minute averaged data were extracted and hourly averages were calculated for hours with

134 more than $70 \%$ of the data availability. The FMPS used in this study was compared against two

135 Scanning Mobility Particle Sizers (SMPS) in Jeong and Evans (2009). While the FMPS and

136 SMPS instruments reported similar total PN concentrations, the shape of the particle size

137 distributions differed due to limitations in the FMPS inversion algorithm. In this study, the

138 empirical correction factors developed by Jeong and Evans (2009) were applied to the FMPS

139 size bins (8.06 to $93.1 \mathrm{~nm})$ to ensure equivalency between the FMPS and SMPS instruments. The

140 counting efficiency of the FMPS for size bins less than $8 \mathrm{~nm}$ and greater than $300 \mathrm{~nm}$ was low. To

141 ensure consistent results, only particles between 8 and 300nm were included in this study.

144 Particle Counter (WCPC, Model 3781, TSI, Shoreview, MN, USA). This portable WCPC

145 measured particles between 6 and 1000nm. The instrument was operated at 1-minute time

146 resolution. Any observations flagged as erroneous (due to out of range temperature or flow rate

147 values) were removed and not included in the analysis. Hourly average concentrations were

148 calculated for hours with more than $70 \%$ data availability. Side-by-side comparisons between the

149 three WCPCs and FMPS (size bins 8-300nm) showed excellent agreement $\left(\mathrm{R}^{2}=0.92-0.95\right)$. All 
WCPC measurements were scaled by a factor of 1.4 to ensure equivalency with the FMPS. The critical orifice was cleaned after every seven days of field operation.

154 Counter (Model 8285, TSI Incorporated, Shoreview, Minnesota, USA). The P-Trak measured the total particle number concentrations (pt/cm3) for particles between 20 and 1000nm. The P-Trak had an upper limit of 500,000 pt/cm3 and logged data at 10-second time resolution. The P-Trak and FMPS exhibited good correlation for particles greater than $20 \mathrm{~nm}$ when sampling $4 \mathrm{~m}$ from a major arterial roadway ( was observed for particles with diameters greater than $24 \mathrm{~nm}$ suggesting that the size-cut off may be slightly higher than the factory reported value of $20 \mathrm{~nm}$. Given this slope of 1.0, the P-Trak data were used without any scaling. Matson et al. (2004) compared a P-Trak to a Condensation

162 Particle Counter with a size cut-off of 10nm and observed good agreement to within $20 \%$ near 163 traffic sources. Zhu et al. (2006) demonstrated that the P-Trak underestimates the total particle 164 number concentration when sampling freshly emitted particles from traffic sources. The P-Trak was operated for no more than 3 hours on a single charge of alcohol under high relative humidity conditions (greater than $70 \%$ ) to minimize any interference.

\subsection{Data Analysis}

\subsubsection{Mobile Monitoring}

A total of 112 road segments located along ten sampling routes were visited on three

171 separate days between June 13th and August 20th 2008. To ensure sampling occurred under

172 similar meteorological conditions, all measurements were collected on precipitation free days

173 and on days with forecasted afternoon temperatures between 25 and $32^{\circ} \mathrm{C}$. To minimize diurnal

174 influences, measurements were collected on 15 weekday afternoons between 12:00 and 15:00.

175 Two study routes were walked simultaneously. Each sampler carried a GPS unit and log sheets

176 to record their position relative to street addresses and other local features at 1-minute intervals.

177 This manual position logging ensured that the sample locations were well defined in areas with 178 tall buildings. 
The midpoint on each visited road segment was identified and used as an average position on the roadway (average road segment length $=430 \mathrm{~m}$; median $=330 \mathrm{~m}$ ). Routes that followed the same road past multiple major arterial roads were divided into multiple segments at the major arterial roads. The average UFP concentration was calculated for each road segment and matched to the average position on the road. The resulting UFP samples were between 5 and 10 minutes long per road segment. The UFP concentration that was used to produce the LUR model was a three visit average PN concentration for each road segment.

\subsubsection{Central Site and Fixed Sites}

A detailed description of the data treatment at the central site and fixed sites is available in Sabaliauskas et al., (2014). Briefly, the Central site was operated continuously while the fixed site monitors were operated for $1-3$ week intervals throughout the summer of 2008. Only periods with valid data at both the Central site and fixed site were included in the analysis. In each neighbourhood, intermittent sources of UFP were likely present but could not be removed from the data set and may have included emissions from garbage trucks, street cleaning, landscaping services, cooking, individual vehicles and construction. Data were removed from the residential field sites for times during which it was known that the site was influenced by barbequing or lawn maintenance activities as reported by the study volunteers. However, these activities tended to occur during the evenings and on weekends and were for the most part outside of the mobile sampling period of 12:00 to 15:00.

\subsection{Study Method Validation}

A Monte Carlo algorithm was developed to determine the probability that the short duration mobile data is representative of data collected at the fixed sites over longer time horizons. The algorithm was implemented as follows:

1. An overall mean PN concentration was calculated for each of the fixed sites based on all the five minute averaged data collected on weekdays between 12:00 and 15:00.

2. Three five minute averages were randomly selected for a given site from three separate days 
3. The mean value of the three random samples was calculated

4. This process was repeated 100,000 times to ensure that a representative distribution of all possible combinations of the data was generated.

5. A probability distribution of simulated averages was obtained from the 100,000 averages resulting from step 4

6. Based on the probability distribution from step 5, the likelihood that a simulated average would be within $\pm 5 \%, 10 \%, \ldots 95 \%, 100 \%$ of the overall average at each fixed site was

\subsection{Geographical Variables}

The UFP LUR was developed from the mobile measurement data using geographical and socioeconomic data from multiple sources (Table 1) including variables for roadway length,

222 roadway distance, traffic density, land use classification, population characteristics, restaurant 223 density and address density. Circular buffer sizes of 50, 100, 200, 300, 500, 750, 1000, 1500,

2242000,2500 and $3000 \mathrm{~m}$ were examined. All variables were extracted using ArcGIS software

225 (Version 10.1, ESRI, Redlands, CA, 2011). Most predictor variables were derived for different

226 buffer sizes by summing the length of lines (e.g. roads and highways), area (e.g. park area) or the

227 number of points (e.g. number of restaurants) within the circle.

\subsection{Model Development and Validation}

A total of 343 variables were evaluated for inclusion into the land-use regression model. This

232 work applied the model building algorithm described by Henderson et al., (2007) with a slight

233 modification. 1) all variables were ranked by absolute strength of their correlation with the

234 measured pollutant; 2) the highest ranking variable and its corresponding buffer size was

235 identified in each subcategory; 3) within each subcategory, the correlation coefficient was

236 compared to all other variables with smaller buffer sizes; 4) if a variable had a slightly lower

237 correlation with the measured pollutant than the highest ranked variable $(<2 \%$ difference), the

238 variable with the smallest buffer size was selected; 5) variables exhibiting correlation with the

239 highest ranked variable in each subcategory (Pearson's r $>0.6$ ) were removed; 6) all remaining 
variables were entered into a forward stepwise linear regression; 7) variables with insignificant $t$ -

241 statistics ( $>>0.05)$ were removed; 8) Steps 6 and 7 were repeated until convergence and variables

242 that contributed less than $1 \%$ to the $\mathrm{R}^{2}$ were removed; 9) models were rejected if the signs (+/-)

243 of the regression coefficients were inconsistent with a priori assumptions (e.g. sources of UFP

244 should have positive regression coefficients). The outcome was a multiple linear regression

245 model of the form Equation 1:

\section{Equation 1:}

248 UFP Concentration $=$ intercept $+\beta_{1} X_{1}+\beta_{2} X_{2}+\beta_{3} X_{3}+\ldots+\beta_{n} X_{n}+\varepsilon$

249 where $\beta$ is the coefficient for each predictor variable $\mathrm{X}$ and $\varepsilon$ is the random error term.

The LUR model was evaluated using leave-one-out (LOO) cross validation recreating the 252 LUR model with n-1 sites. The predictive power of the LUR model was tested by predicting the 253 UFP concentration measured at the central site and the six residential field sites.

\subsection{UFP Surface Generation}

256 To create the UFP surface, 4000 random points separated by minimum distances of $200 \mathrm{~m}$ were 257 generated within the city limits of Toronto. At each of the 4000 locations, the LUR model's

258 predictor variables were extracted and UFP concentrations were calculated using the LUR 259 model. Universal kriging was applied to the UFP concentration estimates resulting in a 260 representation of the UFP concentrations across Toronto. Maps were truncated to the maximum 261 measured PN concentration during the mobile phase of the study.

\subsection{Results}

\subsection{Mobile Measurements}

The average $\pm 95 \%$ confidence interval for major arterial (>20,000 vehicles per day) and

266 local roads (<2000 vehicles per day) for each neighbourhood are reported in Table 2. In all

267 neighbourhoods, the mean PN concentration on major arterial roadways was higher than on local 268 roads (except Midtown 1, Route 1). The UFP concentration measured on downtown major 
arterial roadways were often 3 to 5 times higher than those in residential areas. Further, major

270 arterial and local roadways located in downtown and mid-town neighbourhoods were

271 significantly higher than those located in areas away from the downtown core.

\subsection{Method Validation: Selected Measurement Period}

The average diurnal trend observed at the central site and six residential sites is presented

275 for weekdays in Figure 3. The diurnal trend presented for the central site encompasses the entire 276 measurement period; however, the shape and magnitude were consistent even when truncated to 277 match the sampling periods of the individual residential sites. The downtown sites (A, B) had 278 similar diurnal behaviour as the central site, while the residential sites (C, D, E, F) exhibited 279 distinctly different behavior, presumably due to differing activities at the sites related to their 280 land use. Across the city, the minimum PN concentration occurred between 4:00 and 6:00 in the 281 morning. The initial increase in PN concentration between 6:00 and 9:00 corresponded to the 282 morning rush hour period. At most sites, the daily maximum PN concentration was observed 283 between 12:00 and 15:00. Although afternoon PN concentration peaks are often associated with 284 particle formation and growth events, simultaneous events of the same magnitude were not 285 observed at the residential sites. On some days, slight increases in PN concentration were 286 observed during the afternoon periods at the residential sites; however, the contribution of these 287 formation events to the overall PN concentration appears to be small.

The mobile measurements were collected between 12:00 and 15:00 (Figure 4). At the 290 residential sites (C, D, E, and F), the PN concentrations were significantly lower than those 291 observed at the central site and sites A and B. These concentration differences were likely due to 292 different emissions profiles surrounding the monitoring sites. Further, the PN concentration 293 exhibited relatively stable behaviour between 12:00 and 15:00 (within 20\%) suggesting that the 294 daily maximums have been reached and this period offers an opportunity to study the spatial 295 variation of UFP without the need to correct for diurnal variation. However, the resulting 296 predictive model likely overestimates the 24-hour average. 


\subsection{Method Validation: Sample Time}

Each mobile route was followed on three separate days to capture a range of possible conditions in each neighbourhood. The combination of mobile and fixed site monitoring enabled better quantification of the uncertainties surrounding the mobile measurements. Using the Monte

302 Carlo simulation method described in the methods section, a probability distribution of averages

303 was obtained based on random subsamples from the fixed monitoring sites. The percent of 304 simulated averages that were within $\pm 5 \%, 10 \% \ldots 100 \%$ of the measured mean are presented in 305 Figure 4 for each field site. Notably, at the downtown sites (A, B), there exists high probability $306(>90 \%)$ that the simulated means are within $30 \%$ of the measured PN concentration average.

307 However, at the residential sites, the probability that the simulated means were within $30 \%$ of the measured PN concentration average was between 54 and $74 \%$.

\subsection{The UFP LUR Model}

311 Table 3 summarizes the LUR model obtained from the mobile PN concentration data. The model

312 has an $\mathrm{R}^{2}=0.72$ and a leave one out ( $\left.\mathrm{LOO}\right)$ cross validation $\mathrm{R}^{2}=0.68$. Variance inflation 313 factors (VIF) were < 5 (ranged from 1.37 to 4.07) suggesting limited collinearity among model

314 variables. There was spatial autocorrelation of the PN concentrations (Moran's I = 0.73) and no 315 spatial autocorrelation of the residuals (Moran's I = -0.09).

317 The parameters included in the model were related to population density, dwelling density, 318 roadway length and resource and industrial activities. Two traffic related parameters were 319 included in the model: length of major arterial roadways and highways within 300m and within $320300-3000 \mathrm{~m}$. In the initial development of stages of the LUR model, a single road length 321 parameter was included (3000m buffer); however, the PN concentrations on major arterial 322 roadways were consistently underestimated. Upon separating the two traffic-related terms, the 323 total model $\mathrm{R}^{2}$ increased by $2 \%$ and the predictive power of the model for PN concentration data

324 collected on major roadways improved. Although resource and industrial area within 1000m was 325 a good predictor variable, Toronto does not have many large emitting facilities. The roadways in 326 and near areas with resource and industrial land use are known to have more heavy duty diesel 
327 truck traffic than other areas in the city (Roorda et al., 2010). Thus the resource and industrial 328 land area parameter may be a partial proxy variable for freight traffic.

\subsection{Mapping UFP}

Figure 5 shows PN concentration distribution across Toronto during summer between 12:00 and 15:00. The map suggests that the PN concentration in Toronto may vary by as much as

333 a factor of 10 during the afternoons. The highest PN concentrations were observed in the 334 downtown core (near the central site, sites A and B), near the highway junction points and 335 around industrialized areas in the city. The PN concentrations were slightly higher on the west 336 side of the city. The lowest PN concentrations were found along the shore of Lake Ontario to the 337 east of the city.

\subsection{Model Evaluation}

The LUR model developed for Toronto had a total model $\mathrm{R}^{2}=0.72$. The individual models developed for the LOO cross-validation had $\mathrm{R}^{2}$ values ranging from 0.72 to 0.76 and

342 RMSE values ranging from 3,150 to 3,380 $\mathrm{cm}^{-3}$ or between 23 and $25 \%$ of the average measured

343 PN concentration. This study benefited by collecting measurements at approximately the same

344 time every day to avoid needing to apply temporal correction factors and by visiting each road segment on multiple days to avoid the need to correct for day-to-day variability. period 12:00 - 15:00, lower: 24-hour average). Overall excellent agreement was observed between the measured and predicted PN concentrations. The LUR model surface had stronger predictive power for measurements collected between 12:00 - 15:00 $\left(\mathrm{R}^{2}=0.86\right)$ than the 24-hour average regression $\left(\mathrm{R}^{2}=0.72\right)$. The LUR model surface had higher $\mathrm{R}^{2}$ values than the manual

352 calculation of UFP concentrations at the fixed sites (afternoon manual calculation $R^{2}=0.76$

353 versus surface $R^{2}=0.86$ and 24 hour average manual calculation $R^{2}=0.65$ versus surface $R^{2}=$ 354 0.72) but similar slopes. The LUR model overestimated the 24-hour average PN concentration at 355 the fixed site by a factor of 1.28. This is unsurprising since the mobile measurements were 356 collected during the afternoon when the PN concentration is likely to be highest. 


\subsection{Discussion}

Initial efforts to develop a UFP LUR model focused on normalizing the mobile PN concentration data with simultaneous measurements collected at the central site. This effort was ultimately abandoned because the central site was located $20 \mathrm{~m}$ from a major arterial roadway and the impacts of individual vehicles disproportionately skewed the results. In future studies, an urban background monitoring site might prove to be appropriate to minimize the impacts of dayto-day variability in PN concentration. This study demonstrates that LUR modelling can be successfully applied to raw mobile UFP concentration data $\left(\mathrm{R}^{2}=0.72\right.$, validated $\left.\mathrm{R}^{2}=0.68\right)$ provided that the measurements are collected at the same time of day and under similar meteorological conditions. The Toronto LUR model has a similar $\mathrm{R}^{2}$ value as the Hoek et al., (2011) model for Amsterdam $\left(\mathrm{R}^{2}=0.65\right)$ and considerably higher $\mathrm{R}^{2}$ values than the LUR models developed by Abernethy et al., (2012) for Vancouver, Canada $\left(R^{2}=0.34-0.53\right)$ and by Rivera et al., (2012) for multiple urban areas in Spain $\left(\mathrm{R}^{2}=0.13-0.63\right)$.

The need to optimize monitoring strategies to balance the competing needs of temporal and spatial coverage to produce an UFP LUR is an ongoing challenge. This work applied a mobile data collection strategy to produce an UFP LUR model. While each sampling route was

375 followed at the same time each day and on three separate days, the optimal sampling time and number of repetitions was unknown a priori. Other studies have applied short duration data collection strategies to produce UFP LUR models. Rivera et al., (2012) visited 644 locations on

378 one occasion to develop an UFP LUR model for multiple towns in Spain. For a small subset of the sites (25 locations), measurements were collected on two sampling days. However, the measured UFP concentration on day 1 and day 2 exhibited limited correlation. Abernethy et al., (2012) collected UFP concentrations at 20 locations over one hour intervals on two separate

382 occasions. Van Poppel et al., (2013) collected mobile measurements on 10 days (twice daily) 383 using a bicycle and found substantial variability within 6 study zones. Notably, each zone had 384 different traffic influence and required a different number of repetitions and background 385 correction before an average that was representative of the 20 sample mean was collected. 
The results from the Monte Carlo simulation are intended to provide guidance for future mobile field study design. However, since the fixed site measurements were collected at the rear of the study participants' homes, the impacts of traffic at these locations is likely lower than those encountered while walking along roadways. The Monte Carlo simulation performed in this study indicated that the downtown neighbourhoods were more likely to be within $30 \%$ of the long-term average concentration $(>90 \%)$ than the residential neighbourhoods (ranging from 54 to $74 \%)$. Although the variability at the residential sites (C, D, E, F) was considerably higher than observed at the downtown sites (A, B), this simulation may represent a worst case scenario for mobile studies. At the downtown sites, the traffic intensity is fairly constant. Consequently, when measuring the PN concentration near the downtown core, the likelihood that an individual measurement is skewed due to a local source is low because the source is continuous. In contrast, at the residential sites, significantly fewer vehicles pass the monitoring sites. Since the flow of vehicles is not continuous, these few vehicles have the ability to skew the PN concentration upwards over short time horizons. When walking in the residential areas, times when trucks passed the mobile samplers or times when lawn maintenance was occurring were recorded and subsequently removed from the data set. Since an equivalent record is unavailable for the fixed sites, intermittent sources may broaden the simulated probability distribution. As a result, the likelihood that the measured PN concentration data fall within the $30 \%$ of the longer term average is possibly higher than the simulated means suggest.

Abernethy et al., (2011) observed correlation between PN concentration and the density of fast food restaurants. This study also observed strong correlation between the number of restaurants and PN concentration; however, restaurant density was highly correlated with the length of major roadways and highways. Consequently, restaurant density was not included in this LUR model due to the likelihood that vehicles were the more dominant source of UFP. However, with greater spatial coverage in future studies, the relationship between UFP and restaurants may be further elucidated. Photochemical nucleation events have been previously reported in Toronto and the surrounding areas in Southern Ontario (Jeong et al., 2010; Yun et al., 2014). These events are characterized by a sudden increase in PN concentrations with diameters less than $25 \mathrm{~nm}$ followed 
418 by a period of growth. Previously, these events have been observed simultaneously at multiple 419 sites separated by hundreds of kilometers (Jeong et al., 2010). While the PN concentrations are 420 heterogeneous across Toronto and the rest of Southern Ontario, the PN concentrations become 421 more uniform during these events. In this study, UFP measurements were collected on days

422 without photochemical nucleation events. As a result, the spatial relationships established in this 423 LUR model are likely only valid on event free days.

This study relied on the P-Trak condensation counter with a lower size cut-off of 20nm.

426 Previous investigation of UFP in Toronto and other urban areas suggests that the particle size

427 distribution in areas away from traffic is dominated by larger particles (Ketzel et al., 2004a;

428 Sabaliauskas et al., 2012). When walking along roadways far from major traffic sources, a large 429 majority of all the particles are likely captured by the P-Trak. In areas close to major traffic 430 sources, the UFP size distribution shifts towards smaller particles and the P-Trak likely 431 underestimates the total PN concentration. Even though the size cut-off of the P-Trak (>20nm) 432 was higher than the CPC $3786(>6 \mathrm{~nm})$, only a small fraction of the UFP size distribution was 433 less than $20 \mathrm{~nm}$ at the residential sites (C, D, E, F) making the measurements from the two 434 instruments directly comparable. However, in locations closer to major traffic sources, such as 435 the central site and the downtown sites (A and B), particles <20nm were likely present. At the 436 central site (20m from a major arterial road), the average geometric mean diameter was smallest 437 between the hours of 12:00 and 15:00 (mean $=28 \mathrm{~nm})$ and 40\% of all particles were <20nm.

438 Sites A and B were within 30 and 100m of a major arterial roadway, respectively. Given that the 439 developed LUR model only captures particles $>20 \mathrm{~nm}$, the predicted PN concentration at the 440 central site, site A and possibly site B are likely underestimated.

This study presents a first approximation of the range of PN concentrations that are likely 443 present in Toronto. The ability of the UFP LUR model to accurately predict the PN concentration 444 in other seasons remains an open question. At the central site, the PN concentration is between 2 445 and 3 times higher during the winter than the summer due to changes in vehicle emissions, 446 increased residential heating and the increased atmospheric lifetime of UFP (Sabaliauskas et al., 447 2012). Consequently, the spatial relationships established between PN concentrations and traffic448 related and residential area variables will likely differ during the winter. Further, meteorological 
patterns between summers can vary substantially in Toronto. Consequently, the ability to predict

450 summer PN concentrations at different locations in different years based on this LUR alone may 451 not be possible.

\subsection{Conclusions}

This study successfully developed an LUR model for UFP in Toronto, Canada using a combination of fixed site and mobile monitoring $\left(R^{2}=0.72\right.$, validated $\left.R^{2}=0.68\right)$. The predictor variables included population density within 300mn, resource and industrial area within 1000m, residential area within $3000 \mathrm{~m}$ and major road and highway length within 300m and within 300 to

$4583000 \mathrm{~m}$. In addition, this study benefited from a hybrid sampling protocol that balanced the competing needs of maximizing sampling time and spatial coverage to develop a robust LUR model. The need to apply temporal correction factors to the mobile PN concentration data were minimized by collecting measurements at the same time and by selecting days with similar meteorological conditions. Assessing the ability of the LUR model to predict PN concentrations in other seasons and in other years remains an open question.

\subsection{Acknowledgements}

Funding for SOCAAR was provided by the Canada Foundation for Innovation, the

467 Ontario Innovation Trust, and the Ontario Research Fund. This work was supported by the

468 Ontario Ministry of the Environment's Best in Science Research Program. Student stipends were 469 provided by the Ontario Graduate Scholarships in Science and Technology. Special thanks to 470 Matt Roorda for providing access to the micro-trip simulation traffic model and the study 471 participants that volunteered to host the particle counting equipment in their backyards.

\subsection{References}

475 Aalto, P., Hämeri, K., Paatero, P., Kulmala, M., Bellander, T., Berglind, N., Bouso, L., Castaño-

476 Vinyals, G., Sunyer, J., Cattani, G., Marconi, A., Cyrys, J., von Klo, S., Peters, A., Zetzsche, K.,

477 Lanki, T., Pekkanen, J., Nyberg, F., Sjövall, B., Forastiere, F., 2005. Aerosol Particle Number

478 Concentration Measurements in Five European Cities Using TSI-3022 Condensation Particle 
479 Counter over a Three-Year Period during Health Effects of Air Pollution on Susceptible

480 Subpopulations. Journal of the Air \& Waste Management Association, 55, 1064-1076.

481

482 Araujo, J.A., Barajas, B., Kleinman, M., Wang, X., Bennett, B.J, Gong, K.W., Navab, M.,

483 Harkema, J., Sioutas, C., Lusis, A.J., Nel, A.E., 2008. Ambient Particulate Pollutants in the

484 Ultrafine Range Promote early Atherosclerosis and Systemic Oxidative Stress. Circulation

485 Research, 102, 589-596.

486

487 Barone, T, Zhu, Y., 2008. The morphology of ultrafine particles on and near major freeways, 488 Atmospheric Environment, 42, 6749-6758.

490 Bräuner, E., Forchhammer, L., Møller, P., Simonsen, J., Glasius, M., Wåhlin, P., Raaschou491 Nielson, O., Loft, S., 2007. Exposure to Ultrafine Particles from Ambient Air and Oxidative 492 Stress-Induced DNA Damage. Environment Health Perspectives, 115, 1177-1182.

494 Buonocore, J., Lee, H., Levy, J., 2009. The Influence of traffic on Air Quality in an Urban

495 Neighbourhood: A Community-University Partnership. American Journal of Public Health, 99, 496 S629-S635.

497

498 Buzorius, G., Hämeri, K., Pekkanen, J., Kulmala, M., 1999. Spatial variation of aerosol number 499 concentration in Helsinki city. Atmospheric Environment, 33, 553-565.

500

501 City of Toronto Transportation Services Division, 2010. Road Classification System. Available 502 at: http://www.toronto.ca/transportation/road_class/index.htm. Last Accessed: August 2011.

503

504 Cyrys, J., Pitz, M., Heinrich, J., Wichmann, H-E., Peters, A., 2008. Spatial and temporal 505 variation of particle number concentration in Augsburg, Germany. Science of the Total 506 Environment, 401, 168-175.

507 
508 Daigle, C., Chalupa, D., Raymond, G., Morrow, P., Oberdörster, G., Utell, M., Frampton, M., 509 2003. Ultrafine particle deposition in humans during rest and exercise. Inhalation Toxicology, $510 \quad 15,539-552$.

511

512 Delfino, R., Sioutas, C., Malik, S., 2005. Potential role of ultrafine particles in associations 513 between airborne particle mass and cardiovascular health. Environmental Health Perspectives, $514113,934-946$.

515

516 Delfino, R.J., Staimer, N., Tjoa, T., Arhami, M., Polidori, A., Gilen, D.L., Kleinman, M.T., 517 Schauer, J.J., Sioutas, C., 2010. Association of Biomarkers of Systemic Inflammation with 518 Organic Components and Source Tracers in Quasi-Ultrafine Particles. Environmental Health 519 Perspectives, 118, 756-762.

520

521 DMTI CanMap Route Logistics [computer file]. Markham, Ontario: DMTI Spatial Inc. , [2010]

523 DMTI Spatial Incorporated, 2008. DMTI CanMap Route Logistics Toronto (CMA) Subset 524 v2008.3 layer.

525

526 Elder, A., Gelein, R., Silva, V., Feikert, T., Opanashuk, L., Carter, J., Potter, R., Maynard, A., 527 Ito, Y., Finkelstein, J., Oberdörster, G., 2006. Translocation of inhaled ultrafine manganese oxide 528 particles to the central nervous system. Environmental Health Perspectives, 114, 1172-1178.

530 Gilbert N.L., Goldberg M.S., Beckerman, B., Brook, J.R., Jerrett, M. 2005. Assessing spatial 531 variability of ambient nitrogen dioxide in Montéal, Canada, with a land-use regression model. 532 Journal of the Air \& Waste Management Association, 55, 1059-1063.

534 Hammond, D., Jones, S., Lalor, M., 2007. In-vehicle measurement of ultrafine particles on 535 compressed natural gas, conventional diesel and oxidation-catalyst diesel heavy-duty transit 536 buses. Environmental Monitoring and Assessment, 125, 239-246. 
538 Hoek, G., Beelen, R., Kos, G., Dijkema, M., Van Der Zee, S. C., Fischer, P. H., Brunekreef, B.

539 2011. Land Use Regression Model for Ultrafine Particles in Amsterdam, Environmental Science

540 \& Technology, 45, 622-628.

541

542 Holmes, N.S., Morawska, L., Mengersen, K., Jayaratne, E.R., 2005. Spatial distribution of

543 submicrometre particles and $\mathrm{CO}$ in an urban microscale environment. Atmospheric Environment, $544 \quad 39,3977-3988$.

546 Jeong, C-H., Evans, G.J., 2009. Inter-Comparison of a Fast Mobility Particle Sizer and a

547 Scanning Mobility Particle Sizer Incorporating an Ultrafine Water-Based Condensation Particle

548 Counter. Aerosol Science and Technology, 43, 364-373.

Jeong, C-H., Evans, G.J., McGuire, M.L., Chang, R.Y.-W., Abbatt, J.P.D., Zeromskiene, K.,

551 Mozurkewich, M., Li, S.-M., Leaitch, W.R., 2010. Particle formation and growth at five rural

552 and urban sites. Atmospheric Chemistry and Physics, 10, 7979-7995.

554 Jerrett, M., Finkelstein, M.M., Brook, J.R., Arain, M.A., Kanaroglou, P., Stieb, D.M., Gilbert, 555 N.L., Verma, D., Finkelstein, N., Chapman, K.R., Sears, M.R. 2009. A cohort study of traffic556 related air pollution and mortality in Toronto. Environmental Health Perspectives, 117, 772-777.

558 Johansson, C., Norman, M., Gidhagen, L., 2007. Spatial \& Temporal variations of PM10 and 559 particle number concentrations in urban air. Environmental Monitoring Assessment, 127, 447 560487.

562 Jun, Y-S., Jeong, C-H., Sabaliauskas, K., Leaitch, W.R., Evans, G.J., 2014. A year-long 563 comparison of particle formation events at paired urban and rural locations. Atmospheric 564 Pollution Research, 5, 447-454.

566 Kim, S., Shen, S., Sioutas, C., Zhu, Y., Hinds, W., 2002. Size Distribution and Seasonal Trends 567 of Ultrafine Particles in Source and Receptor Sites of the Los Angeles Basin. Journal of the Air $568 \&$ Waste Association, 52, 297-307. 
570 Ketzel, M., Wahlin, P., Kristensson, A., Swietlicki, E., Berkowicz, R., Nielsen, O.J., Palmgren, 571 F., 2004. Particle size distributions and particle mass measurements at urban, near-city and rural

572 level in the Copenhagen area and Southern Sweden. Atmospheric Chemistry and Physics, 4, 281 573292.

574

575 Kittelson, D.B., Watts, W.F., Johnson, J.P., Schauer, J.J., Lawson, D.R., 2006. On-road and 576 laboratory evaluation of combustion aerosols - Part 2: Summary of spark ignition engine results. 577 Journal of Aerosol Science, 37, 931-949.

579 Kulmala, M., Dal Maso, M., Mäkelä, J.M., Pirjola, L., Väkevä, M., Aalto, P., Miikkulainen, P., 580 Hämeri, K., O'Dowd, C.D., 2001. On the formation, growth and composition of nucleation mode 581 particles. Tellus Series B, Chemical and Physical Meteorology 53, 479-490.

583 Kulmala, M., Vehkamäki, H., Petäjä, T., Dal Maso, M., Lauri, A., Kerminen, V.-M., Birmili, W., 584 McMurry, P.H., 2004. Formation and growth rates of ultrafine atmospheric particles: a review of 585 observations. Journal of Aerosol Science, 35, 143-176.

587 Larson, T., Henderson, S., Brauer, M., 2009. Mobile Monitoring of Particle Light Absorption 588 Coefficient in an Urban Area as a Basis for Land Use Regression. Environmental Science \& 589 Technology, 43, 4672-7678.

Matson, U., Ekberg, L., Afshari, A., 2004. Measurement of Ultrafine Particles: A Comparison of 592 Two Handheld Condensation Particle Counters. Aerosol Science and Technology, 38, 487-495.

594 Oberdörster, G., Gelein, R., Ferin, J., Weiss, B., 1995. Association of particulate air-pollution 595 and acute mortality - involvement of ultrafine particles. Inhalation Toxicology, 7, 111-124.

597 Oberdörster, G., Sharp, Z., Atudorei, V., Elder, A., Gelein, R., Kreyling, W., Cox, C., 2004. 598 Translocation of Inhaled Ultrafine Particles to the Brain. Inhalation Toxicology, 16, 437-445. 599 
600 Pope, C.A III, Burnett, R.T., Thun, M.J., Calle, E.E., Krewski, D., Ito, K., Thurston, G.D., 2002.

601 Lung cancer, cardiopulmonary mortality and long-term exposure to fine particulate air pollution.

602 Journal of the American Medical Association, 287, 1132-1141.

604 Pijola, L., Paasonen, P., Pfeiffer, D., Hussein, T., Hämeri, K., Koskentalo, T., Virtanen, A., 605 Rönkkö, T., Keskinen, J., Pakkanen, T.A., Hillamo, R.E., 2006. Dispersion of particles and trace 606 gases nearby a city highway: Mobile laboratory measurements in Finland. Atmospheric

607 Environment, 40, 867-879.

608

609 Puustinen, A., Hämeri, K., Pekkanen, J., Kulmala, M., de Hartog, J., Meliefste, K., ten Brink, H., 610 Kos, G., Katsouyanni, K., Karakatsani, A., Kotronarou, A., Kavouras, I., Meddings, C., Thomas, 611 S., Harrison, R., Ayres, J., van der Zee, S., Hoek, G., 2007. Spatial variation of particle number 612 and mass over four European cities. Atmospheric Environment, 41, 6622-6636.

614 Ragettli, M.S., Ducret-Stich, R.E., Foraster, M., Morelli, X., Aguilera, I., Basagaña, X., Corradi, 615 E., Ineichen, A., Tsai, M.-Y., Probst-Hensch, N., Rivera, M., Slama, R., Künzli, N., Phuleria, 616 H.C., 2014. Spatio-temporal variation of urban ultrafine particle number concentrations.

617 Atmospheric Environment 96, 275-283.

619 Rivera, M., Basagaña, X., Aguilera, I., Agis, D., Bouso, L., Foraster, M., Medina-Ramón, Pey, 620 J., Künzli, Hoek, G. (2012). Spatial distribution of ultrafine particles in urban settings: A land 621 use regression model., Atmospheric Environment, 54, 657-666.

623 Roorda, M., Hain, M., Amirjamshidi, G., Cavalcante, R., Abdulhai, B., Woudsma C., 2010.

624 Exclusive Truck Facilities in the Toronto Area: Analysis of Truck and Automobile Demand. 625 Transportation Research Record. Journal of the Transportation Research Board, 2168, 114-128.

626 Sabaliauskas, K., Jeong, C.-H., Yao, X., Jun, Y.S., Jadidian, P., Evans G.J., 2012. Five-year 627 roadside measurements of ultrafine particles in a major Canadian city. Atmospheric Environment $628 \quad 49,245-256$. 
630 Sabaliauskas, K., Jeong, C.-H., Yao, X., Evans, G.J., 2014. The Application of Wavelet 631 Decomposition to Quantify the Local and Regional Sources of Ultrafine Particles in Cities, 632 Atmospheric Environment, 95, 249-257.

634 Shi, J.P., Evans, D.E., Khan, A.A., Harrison, R., 2001. Source and concentration of naoparticles 635 (<10-nm Diameter) in the Urban Atmosphere. Atmospheric Environment, 35, 1193-1202.

637 Sioutas, C., Delfino, R., Singh, M., 2005. Exposure assessment for atmospheric ultrafine 638 particles UFPs. and implications in epidemiologic research. Environmental Health Perspectives, $639113,947-955$.

641 Statistics Canada, 2007. Toronto, Ontario (table). 2006 Community Profiles. 2006 Census.

643 Statistics Canada Catalogue no. 92-591-XWE. Ottawa. Released March 13, 2007.

645 Su, J.G., Jerrett, M., Beckerman, B., Verma, D., Arain, M.A., Kanaroglou, P., Stieb, D., 646 Finkelstein, M., Brook, J., 2010. A land use regression model for predicting ambient volatile 647 organic compound concentrations in Toronto, Canada.

649 Wang, Y., Hopke, P.K., Chalupa, D.C., Utell, M.J., 2011a. Effect of the Shutdown of a Coal650 Fired Power Plant on Urban Ultrafine Particles and Other Pollutants. Aerosol Science and 651 Technology, 45, 1245-1249.

653 Wang, Y., Hopke, P.K., Chalupa, D., Utell, M.J., 2011b. Long-term study of urban ultrafine 654 particles and other pollutants. 45, 7672-7680.

656 Weichenthal, S., Farrell, W., Goldberg, M., Joseph, L., Hatzopoulou, M., 2014. Characterizing 657 the impact of traffic and the built environment on near-road ultrafine particle and black carbon 658 concentrations. Environmental Research 132, 305-310. 
660 Van Poppel, M., Peters, J., Bleux, N., 2013. Methodology for setup and data processing of 661 mobile air quality measurements to assess the spatial variability of concentrations in urban 662 environments. Environmental Pollution 183, 224-233.

663

664 Yao, X., Lau, N.T., Fang, M., Chan, C.K., 2007. Correlations of ambient temperature and 665 relative humidity with submicron particle number concentration size distributions in on-road 666 vehicle plumes. Aerosol Science and Technology, 41, 692-700.

667

668 Zhu, Y., Hinds, C., Kim, S., Sioutas, C., 2002a. Concentration and Size Distribution of Ultrafine 669 Particles Near a Major Highway. Journal of the Air \& Waste Management Association, 52, $670 \quad 1032-1042$.

671

672 Zhu, Y., Hinds, W., Kim, S., Shen, S., Sioutas, C., 2002b "Study of ultrafine particles near a 673 major highway with heavy-duty diesel traffic. Atmospheric Environment, 36, 4323-4335.

674

675 Zhu, Y., Yu, N., Kuhn, T., Hinds, W., 2006. Field comparison of P-trak and Condensation 676 Particle Counters. Aerosol Science and Technology, 40, 422-430. 